\title{
Retraction: Using artificial neural network for forward kinematic problem of under-constrained cable robots
}

\author{
Mohammad Heidari ${ }^{1}$, Seyed Mohammad Reza Faritus ${ }^{2}$, Stanford Shateyi ${ }^{3}$ \\ ${ }^{1}$ Department of Mechanical Engineering, Aligudarz Branch, Islamic Azad University, Aligudarz, Iran \\ ${ }^{2}$ Faculty of Engineering, Shahrekord University, Shahrekord, Iran \\ ${ }^{3}$ Department of Mathematics, University of Venda, P. Bag X5050, Thohoyandou, 0950, South Africa \\ ${ }^{1}$ Corresponding author \\ E-mail: ${ }^{1}$ m.heidari@iau-aligudarz.ac.ir, ${ }^{2}$ mr_faritus@yahoo.com, ${ }^{3}$ Stanford.Shateyi@univen.ac.za
}

DOI https://doi.org/10.21595/jve.2018.20336

Check for updates

\section{Publisher's note regarding paper}

Heidari Mohammad, Reza Faritus Seyed Mohammad, Shateyi Stanford Using artificial neural network for forward kinematic problem of under-constrained cable robots. Journal of Vibroengineering, Vol. 20, Issue 1, 2018, p. 385-400, https://doi.org/10.21595/jve.2017.18633.

\section{The description of the retraction}

Retraction Date: October 28, 2018

Retraction Requested By: Editor in Chief and the Publisher

Retraction Type: Plagiarism

This paper is retracted because it is partially translated from the thesis published in 2017 (listed below) without any permission from authors, or even citing the reference.

Aflakiyan Ali Dynamic Identification and Control of a Cable Suspended Parallel Robot for Object Tracking Purpose Via Image Processing. Master Thesis of Science in Mechatronics. Supervisors: Dr. Mehdi Tale Masouleh, Dr. Ahmad Kalhor. University of Tehran, Faculty of New Science and Technology, February 2017, (in Persian).

The Publisher has checked the retracted paper for similarity issues using plagiarism detection software, however the mentioned reference was not listed in the similarity report due to the obvious reasons. The similarity issues were raised by one of the supervisor of the thesis.

Considering recommendations from the Committee on Publication Ethics (COPE) this case was clarified as plagiarism. 